\title{
Antibacterial and Antifungal Activity in Leaf, Seed Extract and Seed Oil of Seabuckthorn (Hippophae salicifolia D. Don) Plant
}

\author{
Sanjay Mohan Gupta ${ }^{1}$, Atul K Gupta², Zakwan Ahmed ${ }^{1}$ and Anil Kumar ${ }^{2 *}$
}

${ }^{1}$ Molecular Biology and Genetic Engineering Laboratory, Defence Institute of Bio-Energy Research (DIBER), DRDO, Haldwani-263139, India ${ }^{2}$ Department of Molecular Biology \& Genetic Engineering, C.B.S \& H, G.B. Pant University of Agriculture \& Technology, Pantnagar-263145, India

\begin{abstract}
The antibacterial and antifungal efficacy of crude leaf and seed extract and seed oil of Seabuckthorn (Hippophae salicifolia D. Don) on different microbial cultures causing infections/diseases was investigated by agar disc diffusion method. Kanamycin $(1000 \mu \mathrm{g} / \mathrm{ml})$ and clotrimazole $(100 \mu \mathrm{g} / \mathrm{ml})$ was used as standards drug for antibacterial and antifungal assay, respectively. The inhibition zones ranged from 7 to $23 \mathrm{~mm}$ for antibacterial and from 10 to 27 $\mathrm{mm}$ for antifungal activity, respectively. Among all extracts tested, seed extract showed significant and leaf extract showed intermediate activity against both gram-positive bacteria. Whereas, no activity was observed against all test extracts in gram-negative bacteria except in case of Agrobacterium tumefaciens some activity was obtained against seed extract of $H$. salicifolia. In case of fungal cultures, among all test extracts only seed extract showed significant activity against Mucor and Tilletia fungus, while in case of Rhizopus no activity was observed against all test extracts. These results indicated the possibility of using $\mathrm{H}$. salicifolia extract and seed oil for medicinal uses and natural food preservation.
\end{abstract}

Keywords: Antimicrobial activity; Seabuckthorn; Hippophae salicifolia D. Don; Crude leaf and seed extract; Seed oil; Agar disc diffusion assay

\section{Introduction}

Bacterial and fungal infection has been a major problem considered for decades that causes spoilage of food products and various diseases in plants, insects and humans, which leads to significant losses in the crop productivity and health problems worldwide. The demand for non-toxic, natural preservative has been rising with increased awareness and report of ill-effects of synthetic chemical present in food [26]. Moreover, the use of higher plants and preparation made from them to treat infections is an age-old practice in a large part of the world population, especially in developing countries, where there is dependence on traditional medicine for a variety of diseases. Therefore, interest in plants with antimicrobial properties has revived as a consequence of current problems associated with the use of antibiotics. In addition, many compounds present in medicinal plants have been reported to be biologically active with antimicrobial, allopathic, antioxidant and bio-regulatory properties [24].

Seabuckthorn (SBT, Elaeagnaceae family) is a medicinal dioecious shrub or small sized tree of region (2000-4500 m above sea level) of China and Russia with wide but fragmented distribution in Eurasia between 27 and $69^{\circ} \mathrm{N}$ latitude and $7^{\circ} \mathrm{W}$ and $122^{\circ} \mathrm{E}$ longitude [19] and having 6 species and 12 sub-species of SBT [11]. H. salicifolia is less explored species of SBT, cultivated at low altitude (2000-3600 m above sea level) region of Eurasia, mainly in central and east Asia and in north-west Himalayan region from Pakistan to Himanchal Pradesh, Uttarakhand, Nepal and eastern India [11,28]. The main advantage of H. salicifolia is that it is nearly thorn less, and vitamin C content is the highest among all species of SBT [1].

SBT plant has been used extensively in oriental traditional system of medicine for treatment of asthma, skin diseases, gastric ulcers, lung disorders, cough, diarrhoea, and menstrual disorder [31,17]. All parts of the plant are considered to be rich source of a large number of bioactive substances like flavonoids (isorhamnetin, quercetin, myricetin, kaempferol and their glycoside compounds), carotenoids ( $\beta$ and $\delta$-carotene, lycopene), vitamins (C, E, K), tannins, triterpenes, glycerides of palmitic, stearic and oleic acids, and some essential amino acids and many more [29]. The bioactive substances are in great demand due to its extensive biological properties and providing source of discovery of many type effective herbal formulation based drugs. These drugs are safe and having negligible or no side effect in compression to synthetic drug. SBT natural bioactive compounds have been found to possess significant anti-microbial, anti-oxidative, antiinflammatory, immunomodulatory, radio-protective, adaptogenic and tissue regenerative properties $[7,6,13,4,20]$. For the past of 50 year more than 300 medical preparations of SBT have been clinical used to treat various diseases $[11,15,20]$. Although still, there is a need to identify novel potential antimicrobial bioactive compounds from SBT having better nutraceutical and therapeutic importance.

Antimicrobial and antioxidant properties of various extracts and oils have been studies and well characterized in H. rhamnoides species of SBT but there are fewer reports are available on bio-prospecting of $H$. salicifolia species, for its functional attributes. Therefore, the present study was aimed to evaluate the antimicrobial activity of crude leaf and seed extract and seed oil of $H$. salicifolia against different pathogens for their potential as a natural preservative and for the development of herbal formulations for future drug development.

\section{Materials and Methods}

Bacterial cultures namely, Bacillus subtilis (NCTC 10073), Bacillus thuringiensis (MTCC 4714), Pseudomonas fluorescens (NCTC 10038), Escherichia coli (NCTC 9002), Agrobacterium tumefaciens (MTCC 609) and Acinetobactor junii (MTCC 1686) and fungal cultures

*Corresponding author: Anil Kumar, Department of Molecular Biology \& Genetic Engineering, C.B.S \& H, G.B. Pant University of Agriculture \& Technology, Pantnagar-263145, India, Tel: (0091-5944) 233898; Fax: (0091-5944) 233287 E-mail: anilkumar.mbge@gmail.com

\section{Received May 04, 2011; Accepted June 28, 2011; Published July 07, 2011}

Citation: Gupta SM, Gupta AK, Ahmed Z, Kumar A (2011) Antibacterial and Antifungal Activity in Leaf, Seed Extract and Seed Oil of Seabuckthorn (Hippophae salicifolia D. Don) Plant. J Plant Pathol Microbiol 2:105. doi:10.4172/21577471.1000105

Copyright: @ 2011 Gupta SM, et al. This is an open-access article distributed under the terms of the Creative Commons Attribution License, which permits unrestricted use, distribution, and reproduction in any medium, provided the original author and source are credited. 
namely, Rhizopus oryzae (MTCC 262), Mucor indicus (MTCC 3318) and Tilletia indica were obtained from Department of Molecular Biology Genetic Engineering, G B Pant University of Agriculture \& Technology, Pantnagar.

H. salicifolia leaves were collected from DIBER Field Station, Auli, where the plant grows wildly under natural conditions. The fresh leaves $(5 \mathrm{~g})$ were ground in porcelain mortar and the leaf paste was squeezed through muslin cloth to give fresh crude leaf extract and $10 \mu \mathrm{l}$ of the extract was applied on disc 1 (6 mm, Himedia). The same extract was concentrated four fold in centrivap concentrator (Labconco, Biogentek, India) and $10 \mu \mathrm{l}$ of this was applied on disc 2 . The extract was also dried completely in centrivap concentrator and dissolved in $50 \mu \mathrm{l}$ of Di-methyl Sulphoxide (DMSO) by keeping the tubes in the water bath at $37^{\circ} \mathrm{C}$ for one hour and cleared by centrifugation at 10,000 $\mathrm{g}$ for $2 \mathrm{~min}$ and $10 \mu \mathrm{l}$ of the supernatant was applied on disc 3 . Clarified crude leaf extract (centrifuged at $10000 \mathrm{~g}$ for $10 \mathrm{~min}$ ) was concentrated four fold in centrivap concentrator and $10 \mu \mathrm{l}$ of this was applied on disc 4. The remaining aliquot of this supernatant was dried completely in centrivap concentrator and dissolved in $50 \mu \mathrm{l}$ of DMSO as described earlier and $10 \mu \mathrm{l}$ of this was applied on disc 5. Standard antibacterial (Kanamycin, $1000 \mu \mathrm{g} / \mathrm{ml}$ ) and antifungal (Clotrimazole, $100 \mu \mathrm{g} / \mathrm{ml}$ ) drugs were applied separately on disc 6 as positive control. The DMSO solvent was also applied on disc 7 as negative control. Mature seeds (5g) of $\mathrm{H}$. salicifolia were also ground in porcelain mortar using $5 \mathrm{ml}$ DMSO as described earlier to give fresh crude seed extract and 10 $\mu \mathrm{l}$ of the extract were applied on disc 8 . The crude seed extract was concentrated four fold in centrivap concentrator and $10 \mu \mathrm{l}$ of this was applied on disc 9. Dried seeds were ground in porcelain mortar using liquid nitrogen to get powdered and successively extracted in a Soxhlet extractor for $8 \mathrm{~h}$ at $65^{\circ} \mathrm{C}$ with petroleum ether for the extraction of SBT seed oil according to the standard procedure of Soxhlet [25] and $10 \mu \mathrm{l}$ of fresh seed oil was applied on disc 10.

In vitro antimicrobial studies were carried out on different bacterial and fungal cultures against standard drugs (Kanamycin and Clotrimazole) and test extracts (leaf, seed extract and seed oil) of SBT by agar disc diffusion assay method [9]. A $100 \mu$ l aliquots of bacterial (about $10^{6} \mathrm{cells} / \mathrm{ml}$ ) and fungal cultures (about $10^{8} \mathrm{cfu} / \mathrm{ml}$ ) were evenly spreaded on to LA (Luria agar, Himedia) and PDA (Potato dextrose agar, Himedia) plates (90 $\mathrm{mm}$ diameter) using a sterile glass rod spreader, respectively. The plates were left at room temperature for $15 \mathrm{~min}$. to allow the agar surface to dry. The sterile disc containing the standard drug and test compounds were placed on the inoculated plates. The LA and PDA plates were incubated at $37^{\circ} \mathrm{C}$ and $30^{\circ} \mathrm{C}$ for 24 and $48 \mathrm{~h}$, respectively. Experiment was performed under strict aseptic conditions. Cleared zones were scored as antimicrobial activity of standard drug and test compounds against different tested microorganisms. The antibacterial and antifungal activity was evaluated by measuring the diameter of the inhibition zone [2]. According to Baur's method the microbicidal activity is classified into resistant if the zone of inhibition in millimeter is less than 7. If it is 7-9 $\mathrm{mm}$ intermediate, if the inhibition is 10 or more it is sensitive. The minimum inhibitory concentration (MIC100) was reported as the lowest concentration of the drug capable of inhibition of complete growth of the microorganism being tested. The experiments were performed in triplicate and the data were calculated as mean $\pm \mathrm{SD}$.

\section{Results and Discussion}

The MIC100 of standard drugs (Kanamycin and Clotrimazole) was calculated against all tested microorganisms before conducting experiments with SBT test extracts. The MIC100 values, with respect to Kanamycin for B. subtilis, B. thuringiensis, P. fluorescens, E. coli, A. tumefaciens and $A$. junii were found to be $0.25,0.5,1.0,1.25,1.25$ and $2.0 \mu \mathrm{g}$, respectively, (Figure 1). Whereas, the MIC100 values with respect to Clotrimazole for $R$. oryzae, $M$. indicus and $T$. indica were found to be $0.1,0.1$ and $20 \mu \mathrm{g}$, respectively, (Figure 2). These results indicate that gram-positive bacteria (B. subtilis and B. thuringiensis) were the most susceptible to the Kanamycin drug and having lower MIC100 values. While, gram-negative bacteria (P. fluorescens, E. coli, A. tumefaciens and A. junii) were found more resistant to kanamycin drug and having higher MIC100 values in comparison to gram-positive bacteria. On other hand among fungal cultures, T. indica was found more resistant to Clotrimazole drug and having 200 times higher MIC100 values in comparison to $R$. oryzae and M. indicus.

In our experiment among 8 extracts tested, 3 extracts (Dried supernatant of fresh crude leaf extract dissolved in DMSO, fresh crude seed extract and concentrated crude seed extract) showed significant and 2 extracts (Dried crude leaf extract dissolved in DMSO and concentrated supernatant of fresh crude leaf extract) showed intermediate activity against both gram-positive bacteria $(B$. subtilis and B. thuringiensis). On other hand, no activity was observed against all test extracts in gram-negative bacteria except in case of $A$. tumefaciens some activity was obtained against crude (Disc 8) and concentrated seed extract (Disc 9) of SBT (Table 1). Higher resistance of gram-negative bacteria to external agents has been earlier reported and it is attributed to the presence of lipopolysaccharides in their outer membrane, which make them inherently resistance to antibiotic, detergent and hydrophilic dyes [14]. Similar trend for inhibition of bacterial growth have been observed in earlier studies with SBT

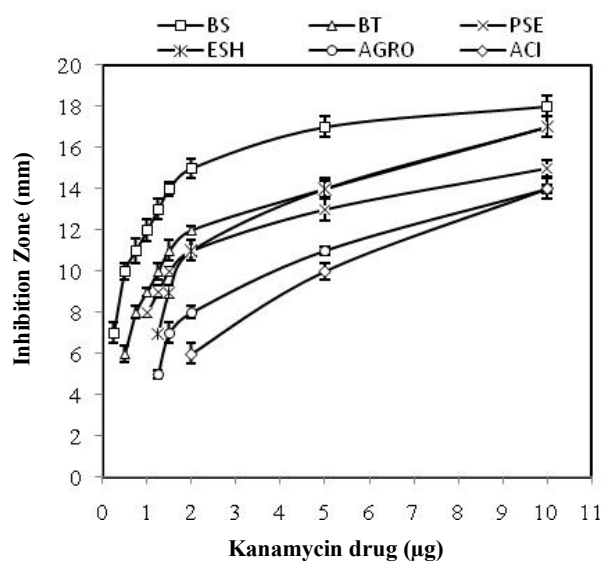

Figure 1: Kanamycin drug sensitivity test against different bacterial strains. The experiments were conducted in triplicates and the data were calculated as mean $\pm S D$
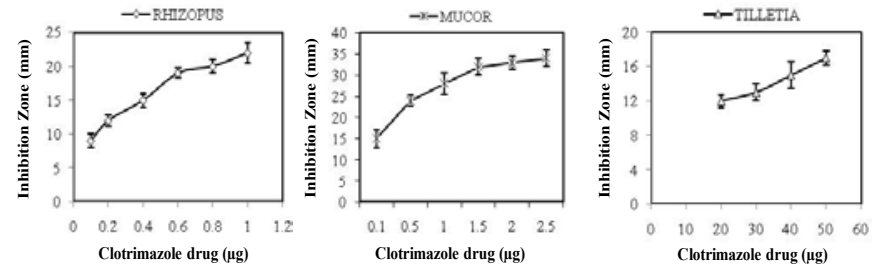

Figure 2: Clotrimazole drug sensitivity test against different fungal strains. The experiments were conducted in triplicates and the data were calculated as mean $\pm \mathrm{SD}$. 


\begin{tabular}{|c|c|c|c|c|c|c|c|c|c|c|}
\hline \multirow[t]{2}{*}{ Disc No. } & \multirow[t]{2}{*}{ Compound } & \multicolumn{6}{|c|}{$\begin{array}{l}\text { Antibacterial activity } \\
\text { (Diameter of inhibition zone in } \mathrm{mm} \text { ) }\end{array}$} & \multicolumn{3}{|c|}{$\begin{array}{l}\text { Antifungal activity (Diameter } \\
\text { of inhibition zone in } \mathrm{mm} \text { ) }\end{array}$} \\
\hline & & BS & BT & PSE & ESH & AGRO & $\mathrm{ACl}$ & RHI & MUC & TILL \\
\hline 1 & Fresh crude leaf extract & - & - & - & - & - & - & - & - & - \\
\hline 2 & Concentrated crude leaf extract & - & - & - & - & - & - & - & - & - \\
\hline 3 & Dried crude leaf extract dissolved in DMSO & $7 \pm 0.2$ & $7 \pm 0.3$ & - & - & - & - & - & - & - \\
\hline 4 & Concentrated supernatant of fresh crude leaf extract & $8 \pm 0.4$ & $7 \pm 0.2$ & - & - & - & - & - & - & - \\
\hline 5 & Dried supernatant of fresh crude leaf extract dissolved in DMSO & $10 \pm 0.1$ & $9 \pm 0.4$ & - & - & - & - & - & - & - \\
\hline 6 & Standard drug & $20 \pm 0.7$ & $18 \pm 0.8$ & $16 \pm 0.5$ & $18 \pm 0.6$ & $23 \pm 0.4$ & $16 \pm 0.2$ & $24 \pm 0.3$ & $27 \pm 0.4$ & $17 \pm 0.2$ \\
\hline 7 & DMSO & - & - & - & - & - & - & - & - & - \\
\hline 8 & Fresh crude seed extract & $11 \pm 0.6$ & $13 \pm 0.5$ & - & - & $12 \pm 0.4$ & - & - & $10 \pm 0.3$ & - \\
\hline 9 & Concentrated crude seed extract & $12 \pm 0.5$ & $14 \pm 0.6$ & - & - & $13 \pm 0.2$ & - & - & $14 \pm 0.2$ & $11 \pm 0.4$ \\
\hline 10 & Seed oil & - & - & - & - & - & - & - & - & - \\
\hline
\end{tabular}

$\mathrm{BS}=$ Bacillus subtilis, BT = Bacillus thuringiensis, PSE = Pseudomonas fluorescens, ESH = Escherichia coli, AGRO = Agrobacterium tumefaciens, ACI = Acinetobactor junii, $\mathrm{RHI}=$ Rhizopus oryzae, MUC = Mucor indicus and TILL = Tilletia indica. The experiments were conducted in triplicates and the data were calculated as mean \pm SD

Interpretations of the results: Among all extracts tested, seed extract showed significant and leaf extract showed intermediate activity against both gram-positive bacteria. Whereas, no activity was observed against all test extracts in gram-negative bacteria except in case of $A$. tumefaciens some activity was obtained against seed extract of $H$. salicifolia. In case of fungal cultures, among all test extracts only seed extract showed significant activity against Mucor and Tilletia fungus, while in case of Rhizopus no activity was observed against all test extracts.

Table 1: Antibacterial and antifungal activity in leaf, seed extract and seed oil of Seabuckthorn (Hippophae salicifolia D. Don).

berry extracts [16] and other plant extract [12]. The reason for higher sensitivity of the gram-positive bacteria than negative bacteria could be ascribed to the differences between their cell wall compositions. The gram-positive bacteria contain an outer peptidoglycan layer, which is an ineffective permeability barrier [22]. In case of fungal cultures, among all test extracts only two compounds, crude seed extract (Disc 8) and concentrated crude seed extract (Disc 9) showed significant activity against Mucor and Tilletia fungus, while in case of Rhizopus no activity was observed against all test extracts. Concentrated crude seed extract (Disc 9) of SBT exhibited highest antifungal and antibacterial activity as compared to other extract tested. The inhibition zones ranged from 7 to $23 \mathrm{~mm}$ for antibacterial and from 10 to 27 for antifungal activity, respectively. Hence in this study leaf, seed extracts and seed oil of SBT gives sensitive microbicidal activity.

Among different species of SBT, $H$. salicifolia showed higher total phenolic compounds in the leaf and seed tissues [11]. We propose that higher antibacterial and antifungal activities of crude seed extract of $\mathrm{H}$. salicifolia may be due to the higher phenolic content. Patro et al. [15] concluded that higher antioxigenic activity of SBT berry is due to higher contents of flavonoids. Rosch et al. [18] observed that although a few phenolic compounds present in SBT fruit juice have good antioxidant capacity, their contribution to the antioxidant effect is meager in compression to ascorbic acid. Negi et al. [13] also studied the antibacterial activity of chloroform, ethyl acetate, acetone and methanol extracts of SBT seeds. Similarly, Chauhan et al. [3] showed antioxidant and antibacterial activities of aqueous extract of Seabuckthorn seeds. Seed oil of SBT possesses several strong antioxidative and antimicrobial properties, which are due to high content of tocopherols, tocotrienols and carotenoids present in the oil [5]. Omega-3 and 6 fatty acids present in the SBT seed oil is known to moderate anti-inflammatory activity of prostaglandins and also critical to vascular health [32]. The SBT leaves were considered to be rich source of flavonoids (isorhamnetin and quercetin), carotenoids, sterols (free and esterified), triterpenols and isoprenols, which support its medicinal properties such as anti-cancerous, anti-bronchitis, antiinflammatory, wound healing, burns, energizer, memory vitalizer and analgestic properties [8,27]. In addition, antiviral, antimicrobial and other biological activities of SBT leaf extracts was also studied by Shipulina [23]. Flavonoids are one of the major secondary metabolites synthesized by Seabuckthorn. Since they are known to be synthesized by plants in response to microbial infection, they have been found in-vitro to be effective antimicrobial substance against a wide array of microorganisms [29]. The microbicidal activity of Seabuckthorn extracts is probably due to their ability to form complex with extra cellular and soluble proteins and bacterial cell walls by nonspecific forces such as hydrogen bonding and hydrophobic effects, as well as by covalent bond formation. Thus, their mode of antimicrobial actions may be related to their ability to inactive microbial adhesins, enzymes, cell envelope transport proteins and many more. There is also evidence for direct inactivation of microorganisms [21]. Therefore, present observations suggest that $H$. salicifolia is a potential source of bioactive antimicrobial agents, which could be used as a natural preservative and for nutraceutical formulations.

\section{Acknowledgements}

We thank the DRDO, Min. of Defence, Govt. of India for financial support and scientific staff of DIBER is also acknowledged for providing help during the preparation of this manuscript.

\section{References}

1. Ahmed Z, Gupta SM. (2009) Seabuckthorn: A source (donar) in molecular breeding, National conference on Seabuckthorn and Environment, High Altitude Perspectives, DIHAR, Leh-Ladakh-194101 J\&K, India.

2. Baur AW, Kirby WM, Sherris JC, Turck M (1966) Antibiotic susceptibility testing by a standard single disk method. Am J Clin Path 45: 493-496.

3. Chauhan AS, Negi PS, Ramteke RS (2007) Antioxidant and antibacterial activities of aqueous extract of Seabuckthorn (Hippophae rhamnoides) seeds. Fitoterapia 78: 590-592.

4. Chawla R, Arora R, Singh S, Sagar RK, Sharma RK, et al. (2007) Radioprotective and antioxidant activity of fractionated extracts of berries of Hippophae rhamnoides. J Med Food 10: 101-109.

5. Chen, YD, Jiang ZR, Qin WI, Ni MN, Li XL, et al. (1990) Research on chemical composition and characteristics of Seabuckthorn berry and its oil. Chem and Indus of Fores Prod 10: 163-175.

6. Ganju L, Padwad Y, Singh R, Karan D, Chanda S, et al. (2005) Anti-inflammatory activity of Seabuckthorn (Hippophae rhamnoides) leaves. Int Immunopharmcol 5: 1675-1684.

7. Geetha S, SaiRam M, Singh V, llavazhagan G, Sawhney RC (2002) Antioxidant and immunomodulatory properties of seabuckthorn (Hippophae rhamnoides L.)-An in vitro study. J. of Ethnopharmacol 79: 373-378.

8. Gupta A, Kumar R, Pal K, Banerjee PK, Sawhney RC (2005) A preclinica study of the effects of Sea buckthorn (Hippophae rhamnoides L.) leaf extract on 
Citation: Gupta SM, Gupta AK, Ahmed Z, Kumar A (2011) Antibacterial and Antifungal Activity in Leaf, Seed Extract and Seed Oil of Seabuckthorn (Hippophae salicifolia D. Don) Plant. J Plant Pathol Microbiol 2:105. doi:10.4172/2157-7471.1000105

cutaneous wound healing in albino rats. Int J.Lower Extrem Wounds 4: 88-92.

9. Gupta S, Kumar N, Gupta SM (2009) Antibacterial and antifungal activity in extract and oil of piper betle landrace bangla mahoba. J. Adv. Zoo 30 (1): 1620.

10. Gupta VN, Nepal VP, Adhikari K, Ghimire S, Subedi CK (2000) An ecological assessment of Seabuckthorn resource in Dolpa and Jumla district of north-west Nepal. TISC/NARMSAP, Kathmandu, Nepal.

11. Lu R (1992) Seabuckthorn: A multipurpose plant species of fragile mountains, ICIMOD Occasional paper No.20, Katmandu, Nepal, p 62.

12. Negi PS, Chauhan AS, Sadia GA, Rohinishree YS, Ramteke RS (2005) Antioxidant and antibacterial activities of various seabuckthorn (Hippophae rhamnoides L.) seed extracts. Food Chem 92: 119-124.

13. Negi PS, Jayaprakasha GK (2003) Antioxidant and antibacterial activities of Punica granatum peel extracts. J. of Food Sci 68: 1473-1477.

14. Nikaido H, Vaara M (1985) Molecular basis of bacterial outer membrane permeability. Microbiol. Reviews 49: 1-32.

15. Patro BS, Samuel R, Sreekanth A, Dwivedi SK, Chaurasia OP, et al. (2001) Anti-oxygenic activity of Indian seabuckthorn (Hippophae rahmnoides L.) In V. Singh, P.K. Khosla (Eds.), Seabuckthorn - A resource for health and environment in twenty first century. Proceedings of international workshop on seabuckthorn, Feb. 18-21. CSKHPAU, Palampur and Indian Society of Tree Scientists, Solan, India, p. 194-198.

16. Puupponen-Pimla R, Nohynek L, Meier C,Kahkonen M, Heinonen M, et al (2001) Antimicrobial properties of phenolic compounds from berries. J. of Appl. Microbiol 90: 494-507.

17. Ranjith A, Kumar SK, Venugopalan VV, Arumughan C, Sawhney RC, et al. (2006) Fatty acids, tocols and caratenoides in pulp oil of three seabuchthorn species $(H$. rhamnoides, $H$. salicifolia and $H$. tibetana) grown in the Indian himalayas. JAOCS 83: 359-384

18. Rosch D,Bergmann M, Knorr D, Kroh LW (2003) Structure-antioxidant efficiency relationships of phenolic compounds and their contribution to the antioxidant activity of seabuckthorn juice. J. of Agri. and Food Chem 51: 4233-4239.

19. Rousi A (1971) The genus Hippophae L.: a taxonomic study. Ann. Bot. Fenn 8: $177-227$.
20. Saggu S, Diveker HM, Gupta V, Sawhney RC, Baneriee PK, et al. (2007) Adaptogenic and safety evaluation of Sea buckthorn (Hippophae rhamnoides L.) leaf extract: a dose dependent study. Food Chem. Toxicol 45: 609-617.

21. Scalbert A (1991) Antimicrobial properties of tannin. Photochem 30, 38753883.

22. Scherrer R, Gerhardt $P$ (1971) Molecular sieving by the Bacillus megatrium cell wall and protoplast. J. of Bacteriol 107, 718-735.

23. Shipulina LD (2001) A study of antiviral activity and other biological properties of hiporamin. A new antiviral drug from Seabuckthorn leaves. In: proceeding of international workshop on Seabuckthorn, New Delhi, Seabuckthorn- A resource for health and environment tin twenty first century (V. Singh and P.K. Khosla, Eds.) 212-213.

24. Smid EJ, Gorris LGM (1999) Natural antimicrobials for food preservation. In handbook of food preservation (Shaurr Rahman, M., Ed.), Marcel Dekker, New York 285-308.

25. Soxhlet F (1879). Die genichtsanalytische bestimmung des miichfettes. Dingler Poly Technisches J 232- 461.

26. Tauxe RV (1997) Emerging food born diseases: An evolving public health challenge. Dairy Food Environ Sanit 17: 788-795.

27. Upadhyay NK, Kumar R, Siddiqui MS, Gupta A (2009) Mechanism of WoundHealing Activity of Hippophae rhamnoides L. Leaf Extract in Experimental Burns eCAM 1-9.

28. Uprety Y, Asselin H, Boon EK, Yadav S, Shrestha KK (2010) Indigenous use and bio-efficacy of medicinal plants in rasuwa district, Central Nepal. $J$ of Ethnobiol and Ethnome 6:3.

29. Xiao Z (1980) Chemical study on the flavonoids of Hippophae rhamnoides Acad J Sichuan Med Univ (Chinese) 11: 174-176.

30. Xu MY, Sun XX, Tong WX (1994) Medical research and development of Seabuckthorn. Hippophae 7: 32-40.

31. Xu Mingyu (1991) Present conditions and future research on Seabuckthorn medicinal use. J Water Soil Conserv (China) 5-38.

32. Yang B, Kalio H (2001) Fatty acid composition of lipids in Seabuckthorn (Hippophae rhamnoides L.) berries of various origins. J Agric Food Chem 49 1939-1947. 